\title{
Acúmulo de forragem durante a rebrotação de capim-xaraés submetido a três estratégias de desfolhação ${ }^{1}$
}

\author{
Bruno Carneiro e Pedreira ${ }^{2}$, Carlos Guilherme Silveira Pedreira ${ }^{2}$, Sila Carneiro da Silva ${ }^{2}$ \\ 1 Pesquisa financiada pela Fundação de Amparo à Pesquisa do Estado de São Paulo - FAPESP. \\ 2 Departamento de Zootecnia, ESALQ/USP, Av. Pádua Dias, n 11, Piracicaba, SP, CEP: 13420-918.
}

RESUMO - Objetivou-se comparar a dinâmica do acúmulo de forragem em pastos de capim-xaraés [Brachiaria brizantha (A. Rich.) Stapf. cv. Xaraés] submetidos a três estratégias de desfolhação intermitente, uma baseada no calendário (pastejo a cada 28 dias) e duas na interceptação luminosa (IL), aos 95 ou 100\% de interceptação luminosa. A massa de forragem (MF) pré-pastejo foi maior na estratégia de desfolhação aos $100 \%$ de interceptação de luz. Os piquetes pastejados aos $95 \%$ de interceptação de luz e a cada 28 dias apresentaram menores massas de forragem e não diferiram entre si na primavera. O pastejo aos $95 \%$ de interceptação de luz aumentou a proporção de folhas, apesar das menores massas pré-pastejo. O pastejo aos $100 \%$ de interceptação de luz resultou na menor porcentagem de folhas na massa de forragem, indicando que a maior produção total de forragem foi ocasionada pelo maior alongamento de colmos, o que está associado à competição por luz entre as plantas no interior do dossel. O prolongamento do período de descanso para além dos 95\% de interceptação da luz incidente aumenta a massa de forragem na entrada dos animais no momento do pastejo (100\% IL ou a cada 28 dias durante o verão), porém, esse aumento é resultado do acúmulo de colmos e material morto e pode afetar negativamente o valor nutritivo da forragem produzida e o desempenho animal.

Palavras-chaves: altura, composição morfológica, índice de área foliar, interceptação luminosa

\section{Herbage accumulation during regrowth of Xaraés palisadegrass submitted to rotational stocking strategies}

\begin{abstract}
The objective of this research was to describe comparatively the dynamics of herbage accumulation in Xaraés palisadegrass pastures [Brachiaria brizantha (A. Rich.) Stapf cv. Xaraés] submitted to rotational stocking managements, defined either by pre-graze light interception (LI) by the canopy (95\% or 100\% LI) or calendar days (28d) Pre-graze forage mass (FM) was higher for 100\% LI pastures. Pastures grazed at 95\% LI and 28-d resulted in similar pregraze FM in the spring, both lower than that of the 100\%-LI treatment. Grazing at 95\% LI resulted in higher leaf percentage in pre-graze forage, although total pre-graze FM was lower. Forage produced in paddocks grazed at $100 \%$ LI had lower pregraze leaf percentage, indicating that the higher forage accumulation in that treatment was a result of higher stem elongation, likely due to light competition within the canopy. Rest periods beyond the point where swards achieved 95\% LI (100\% LI or 28-d during the summer) resulted in higher accumulation and higher pre-graze FM, although this corresponded mainly to large amounts of stem and dead material, which could negatively affect the nutritive value of the forage produced and animal performance.
\end{abstract}

Key Words: leaf area index, light interception, plant part composition, sward height

\section{Introdução}

A produtividade e a perenidade das pastagens decorrem, entre outros fatores, da capacidade de reconstituição e manutenção da área foliar após a desfolhação. Assim, diferentes freqüências e intensidades de desfolhação têm forte impacto sobre a condição das plantas, determinando sua velocidade de crescimento, produtividade e persistência (Nabinger \& Pontes, 2001).
A caracterização da forragem ofertada aos animais, com base no crescimento e desenvolvimento durante determinado período de rebrotação, pode ser feita por meio do fracionamento da forragem acumulada em estratos horizontais do dossel e também nos componentes morfológicos (folhas, colmos e material morto), possibilitando a caracterização dos padrões e das alterações morfológicas e estruturais da vegetação durante o processo de acúmulo de forragem. Estratégias de manejo contrastantes podem 
resultar em variações na estrutura do dossel, influenciando o desempenho animal, em decorrência dos seus efeitos na quantidade e no valor nutritivo da forragem em oferta e consumida.

O objetivo neste estudo foi avaliar a dinâmica do acúmulo de forragem do capim-xaraés submetido a três estratégias de desfolhação.

\section{Material e Métodos}

O experimento foi conduzido em uma área experimental pertencente ao Departamento de Zootecnia da Escola Superior de Agricultura “Luiz de Queiroz” (ESALQ), localizada no município de Piracicaba, São Paulo, a 580 m de altitude, $22^{\circ} 42^{\prime}$ de latitude sul e $47^{\circ} 30^{\prime}$ de longitude oeste, com características médias das normais meteorológicas correspondentes a precipitação anual de $1.002 \mathrm{~mm}$ (Figura 1) e $23,6^{\circ} \mathrm{C}$ de temperatura média durante o verão (outubro a março). A distribuição da chuva e a evapotranspiração real da cultura (ETR) durante o período experimental foi estimada com base nos dados do posto metereológico da ESALQ. O solo da área experimental é classificado como Nitossolo Vermelho Eutroférrico típico (Embrapa, 1999), com as seguintes características químicas: $\mathrm{pHCaCl}{ }_{2}=5,5$; matéria orgânica $=29 \mathrm{~g} / \mathrm{dm}^{3} ; \mathrm{P}=50 \mathrm{mg} / \mathrm{dm}^{3}$; $\mathrm{K}=6,1 \mathrm{mmol}_{\mathrm{c}} / \mathrm{dm}^{3} ; \mathrm{Ca}=49 \mathrm{mmol}_{\mathrm{c}} / \mathrm{dm}^{3} ; \mathrm{Mg}=18 \mathrm{mmol}_{\mathrm{c}} / \mathrm{dm}^{3}$; $\mathrm{H}+\mathrm{Al}=24 \mathrm{mmol}_{\mathrm{c}} / \mathrm{dm}^{3} ; \mathrm{Al}=0 \mathrm{mmol}_{\mathrm{c}} / \mathrm{dm}^{3} ; \mathrm{SB}=73 \mathrm{mmol}_{\mathrm{c}} / \mathrm{dm}^{3}$; capacidade de troca catiônica $(\mathrm{CTC})=97 \mathrm{mmol}_{\mathrm{C}} / \mathrm{dm}^{3} ; \mathrm{V}=76 \%$ e S-SO $4=28 \mathrm{mg} / \mathrm{dm}^{3}$.

Foram feitas apenas adubações em cobertura, totalizando $120 \mathrm{~kg} /$ ha de $\mathrm{N}$ e $\mathrm{K}_{2} \mathrm{O}$, nas formas de sulfato de amônio e cloreto de potássio, divididos em duas aplicações manuais, metade no início da estação chuvosa (23/9/2005), após pastejo de uniformização $(15 \mathrm{~cm})$, e o restante no meio da estação, entre os dias 3 e 16 de dezembro de 2005. A segunda adubação foi feita na condição pós-pastejo em todas as unidades experimentais.

As estratégias de pastejo rotativo foram caracterizadas pela frequiência de desfolhação (a cada 28 dias) ou pela intensidade de interceptação luminosa (IL) para início da rebrotação (95\% ou $100 \%$ de interceptação da radiação luminosa incidente). A altura pós-pastejo foi de $15 \mathrm{~cm}$ nas três estratégias de desfolhação, de acordo com a recomendação para o capim-xaraés (Embrapa, 2003). As estratégias de desfolhação foram alocadas em unidades experimentais de $120 \mathrm{~m}^{2}$, segundo delineamento inteiramente casualizado com três repetições. O pastejo foi realizado por vacas das raças Holandesa (Bos taurus taurus L.) e Nelore (Bos taurus indicus L.) com peso médio de $350 \mathrm{~kg}$. A técnica de

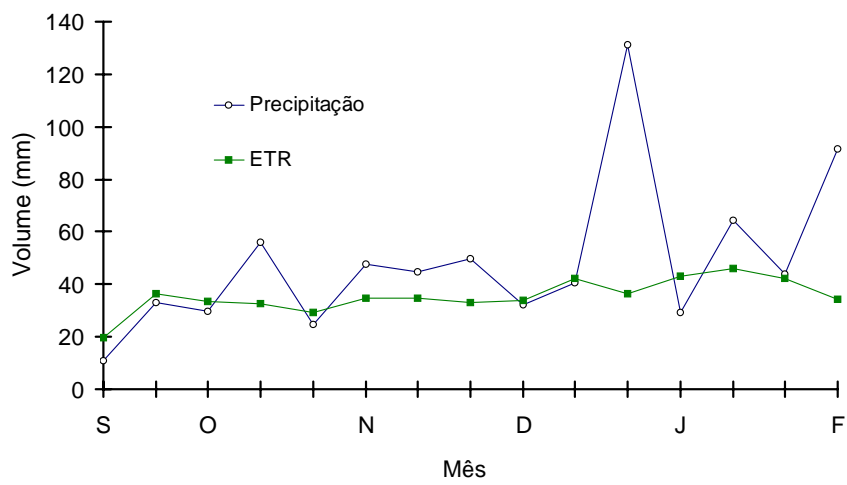

Figura 1 - Balanço hídrico referente ao período experimental, por decêndio.

mob-grazing (Mislevy et al., 1981) foi usada para a realização dos pastejos, empregando-se grupos de animais para desfolhações rápidas (duração de 4 a 20 horas). Cada piquete foi cercado com cerca elétrica para contenção dos animais. À medida que os animais pastejavam, medições de altura eram feitas com régua e transparência até que o dossel atingisse, em média, $15 \mathrm{~cm}$ de altura. Nessas ocasiões, a altura era medida em 20 pontos representativos da condição média do dossel na unidade experimental.

Para as medições de interceptação luminosa pelo dossel, utilizou-se um analisador de dossel, modelo LAI 2000 (Li-Cor, Lincoln Nebraska, EUA), cujo funcionamento foi descrito por Welles \& Norman (1991). Em cada unidade experimental foram tomados 20 pontos representativos da condição média do dossel na ocasião das amostragens, seguindo a relação de uma medida acima para cinco medidas abaixo do dossel, no nível do solo, sempre utilizando pontos entre touceiras. Como o analisador LAI (2000) não registra leituras de intensidade luminosa iguais a zero, mesmo em condições de completa escuridão, a partir do momento em que as leituras apontavam valor acima de $97,5 \%$ de IL por duas vezes consecutivas, o pastejo da área (estratégia de desfolhação aos $100 \%$ de IL) era realizado.

O período experimental foi de 22/9/2005 a 22/2/2006, com duração de 153 dias. Para descrever o acúmulo de forragem durante a rebrotação, realizaram-se avaliações em um ciclo de rebrotação na primavera (outubro/novembro) e um no verão (janeiro/fevereiro), considerados neste estudo “épocas” dentro da estação de pastejo. Em cada uma dessas épocas, foram feitas amostragens para caracterização morfológica e quantificação da massa de forragem (MF) no pós-pastejo, a cada $5 \mathrm{~cm}$ de aumento na altura do dossel durante a rebrotação e no pré-pastejo. No pós-pastejo, a forragem contida no interior de duas molduras retangulares $(0,33 \times 1,20 \mathrm{~m})$ foi cortada rente ao solo. Nas amostragens 
subseqüentes ao pós-pastejo, os estratos horizontais foram colhidos acima da altura de resíduo $(15 \mathrm{~cm})$ a cada $5 \mathrm{~cm}$ de incremento, até que a condição pré-pastejo fosse novamente atingida para realização do último corte. Os locais usados para essas amostragens corresponderam a porções da vegetação representativas da condição dos piquetes no momento da amostragem, segundo avaliação visual. A amostra colhida em cada piquete foi levada ao laboratório para separação manual em lâminas foliares, colmos + bainhas foliares e material morto, por meio de integrador de área foliar, modelo LI-3100 (Li-Cor, Lincoln, Nebraska, EUA). Em seguida, todos os componentes morfológicos foram levados para secagem em estufa de circulação forçada de ar, a $65^{\circ} \mathrm{C}$ até peso constante, e pesados. A área foliar foi usada no cálculo do índice de área foliar (IAF) e, nas ocasiões das amostragens destrutivas, a interceptação luminosa também era medida.

Os dados foram analisados usando-se o procedimento MIXED do programa estatístico SAS ${ }^{\circledR}$ (Littel et al., 2006). Na escolha da matriz de variância e co-variância, utilizou-se o critério de informação de Akaike (Wolfinger, 1993). Assim, foi possível detectar os efeitos da estratégia de pastejo e da época, bem como da interação entre esses fatores. Os efeitos de estratégia de manejo e época do ano e suas interações foram considerados fixos (Littel et al., 2006). As médias das estratégias de desfolhação foram estimadas utilizando-se o LSMEANS e a comparação entre elas foi realizada por meio da probabilidade da diferença (PDIFF) usando o teste Tukey e 10\% de significância.

\section{Resultados e Discussão}

Embora a altura do resíduo de $15 \mathrm{~cm}$ tenha sido aplicada em todas as unidades experimentais, houve efeito da estratégia de pastejo ( $\mathrm{P}=0,0011)$ e da interação estratégia $\times$ época $(\mathrm{P}=0,0747)$ sobre a massa de forragem pós-pastejo (Tabela 1). As estratégias de desfolhação aos $100 \%$ de interceptação luminosa e a cada 28 dias resultaram em intervalos de pastejo mais longos (em média 32 e 28 dias), com massa de forragem pós-pastejo de $4.120 \mathrm{~kg}$ MS/ha, enquanto, na estratégia de desfolhação aos 95\% IL, a massa de forragem pós-pastejo foi de $3.310 \mathrm{~kg}$ MS/ha (Tabela 1).

Quanto maior o intervalo de pastejo, maior a chance de a comunidade vegetal repor as reservas utilizadas na recuperação de um novo dossel. Dependendo desse intervalo - se ele for suficiente para o dossel interceptar quase toda a luz incidente (Mello \& Pedreira, 2004), principalmente em gramíneas forrageiras tropicais -, pode ocorrer o alongamento de colmos, que altera os padrões de acúmulo,
Tabela 1 - Massa total, de material morto e de colmo na forragem pós-pastejo em capim-xaraés submetido a três estratégias de desfolhação

\begin{tabular}{|c|c|c|c|}
\hline \multirow[b]{2}{*}{ Estratégia } & \multicolumn{2}{|c|}{ Estação } & \multirow[b]{2}{*}{ Média } \\
\hline & Primavera & Verão & \\
\hline \multicolumn{4}{|c|}{$\ldots \ldots \ldots$. . $\ldots$ kg MS/ha $\ldots \ldots \ldots$} \\
\hline \multicolumn{4}{|c|}{ Massa total } \\
\hline $95 \%$ IL & $3.400 \mathrm{Aa}$ & $3.220 \mathrm{Ab}$ & $3.310 \mathrm{~b}$ \\
\hline $100 \%$ IL & $3.440 \mathrm{Ba}$ & 4.770Aa & $4.100 \mathrm{a}$ \\
\hline 28 dias & $4.200 \mathrm{Aa}$ & 4.110Aab & $4.150 \mathrm{a}$ \\
\hline Média & $3.680 \mathrm{~B}$ & $4.030 \mathrm{~A}$ & \\
\hline \multicolumn{4}{|c|}{ Material morto } \\
\hline $95 \%$ IL & $1.780 \mathrm{Aa}$ & $1.490 \mathrm{Aa}$ & \\
\hline $100 \%$ IL & $1.530 \mathrm{Ba}$ & $2.200 \mathrm{Aa}$ & \\
\hline 28 dias & $2.020 \mathrm{Aa}$ & $1.890 \mathrm{Aa}$ & \\
\hline \multicolumn{4}{|c|}{ Colmo } \\
\hline $95 \%$ IL & $1.100 \mathrm{Bb}$ & $1.410 \mathrm{Ac}$ & $1.260 \mathrm{~b}$ \\
\hline $100 \%$ IL & $1.540 \mathrm{Ba}$ & $2.220 \mathrm{Aa}$ & $1.880 \mathrm{a}$ \\
\hline 28 dias & $1.670 \mathrm{Aa}$ & $1.850 \mathrm{Ab}$ & $1.760 \mathrm{a}$ \\
\hline Média & $1.440 \mathrm{~B}$ & $1.830 \mathrm{~A}$ & \\
\hline
\end{tabular}

Médias seguidas da mesma letra minúscula na coluna e da mesma letra maiúscula nas linhas não diferem entre si $(\mathrm{P}>0,10)$ pelo teste Tukey.

gerando aumento na massa de forragem do resíduo, provavelmente pelo aumento na massa de perfilhos individuais (Da Silva \& Sbrissia, 2001). Carnevalli et al. (2006), em estudo com capim-mombaça (Panicum maximum Jacq. cv. Mombaça) submetido a estratégias de desfolhação análogas às deste trabalho, encontraram resultado semelhante, uma vez que a massa de forragem pós-pastejo no verão na estratégia de desfolhação aos 95\% IL foi menor que a obtida aos de 100\% IL. Santos et al. (1999), estudando o capim-tanzânia (Panicum maximum Jacq. cv. Tanzânia) sob pastejo rotativo, também observaram aumento significativo na massa de forragem do resíduo com o aumento do período de descanso.

A proporção de folhas foi afetada pela estação, tanto em massa $(\mathrm{P}=0,0684)$ quanto como proporção da massa de forragem pós-pastejo ( $\mathrm{P}=0,0148)$. Em ambos os casos, houve redução, de 470 para $330 \mathrm{~kg}$ MS/ha e de 12,7 para 8,5\% do peso total, da primavera para o verão. O índice de área foliar pós-pastejo reduziu de 0,61 para $0,33(\mathrm{P}=0,0327) \mathrm{e}$ houve interação $(\mathrm{P}=0,0071)$ de estratégia de pastejo e estação do ano para a massa de material morto (Tabela 1). A estratégia de desfolhação aos $100 \%$ IL resultou em aumento na massa de material morto da primavera para o verão, enquanto a proporção de material morto na massa de forragem pós-pastejo foi afetada pela estação $(\mathrm{P}=0,0295)$, mas não pela estratégia de pastejo $(\mathrm{P}=0,6378)$, pois reduziu de 48 para $46 \%$ da massa de forragem pós-pastejo da primavera para o verão. 
A massa de colmos no pós-pastejo (Tabela 1) variou com a estação ( $\mathrm{P}=0,0001)$ e com a estratégia de desfolhação $(P=0,0002)$ e sofreu ainda efeito da interação estação $\times$ estratégia de desfolhação $(\mathrm{P}=0,0108)$. Da primavera para o verão, a massa de colmos aumentou, provavelmente como resposta estímulo ao perfilhamento decorrente da desfolhação (Butler \& Briske, 1988). Além disso, outras variáveis ambientais além da luminosidade (temperatura, condição hídrica) podem atuar no perfilhamento e ser tão importante quanto fatores hormonais no desenvolvimento de gemas e no estímulo ao perfilhamento (Murphy \& Briske, 1992).

Na estratégia de desfolhação aos 95\% IL, apesar do aumento na massa de colmos no pós-pastejo da primavera para o verão (Tabela 1), as quantidades absolutas foram menores que nas demais estratégias de desfolhação, provavelmente em razão da maior freqüência de desfolhação, o que não ocasionou elevadas taxas de alongamento de colmos (Carnevalli et al., 2006), gerando colmos mais jovens e de colheita mais fácil. Na estratégia de desfolhação aos $100 \%$ IL, os maiores intervalos de pastejo resultaram em elevada massa de colmos, enquanto, na estratégia de desfolhação a cada 28 dias, apesar de não ter havido diferença entre as estações, as massas de colmos $(1.760 \mathrm{~kg}$ MS/ha) se mantiveram sempre altas e, em média, foram similares às obtidas com desfolhação aos $100 \%$ de IL (1.880 kg MS/ha).

Na primavera, a fração colmo representava $39,1 \%$ da massa de forragem pós-pastejo e passou a $45,5 \%$ no verão $(P=0,0148)$. A estratégia que possibilitou a maior $(\mathrm{P}=0,0634)$ proporção de colmos na massa de forragem pós-pastejo foi a de desfolhação aos 100\% IL (45,8\%) e a menor, a de desfolhação aos 95\% IL (38,2\%). A desfolhação a cada 28 dias apresentou proporção intermediária $(42,8 \%)$ de colmos na massa de forragem pós-pastejo.

A massa de forragem pré-pastejo foi afetada pela estratégia de pastejo ( $\mathrm{P}=0,0011)$ e também pela interação estratégia $\times$ estação $(P=0,0747)$ (Tabela 2$)$. Em média, os valores de massa de forragem pré-pastejo foram maiores na estratégia de desfolhação aos 100\% IL. As estratégias de desfolhação aos 95\% IL e a cada 28 dias promoveram massa de forragem mais baixas e semelhantes na primavera, o que pode ser parcialmente explicado pelas condições climáticas desfavoráveis ao crescimento em outubro/novembro, notadamente a condição hídrica (Figura 1). No verão, a desfolhação a cada 28 dias resultou em massa de forragem pré-pastejo semelhante às obtidas com base na interceptação luminosa, e o déficit hídrico havia sido suprimido, o que contribuiu para a redução do intervalo de pastejo nas
Tabela 2 - Massa total, de folhas e de colmos na forragem prépastejo ${ }^{1}$ em capim-xaraés submetido a três estratégias de desfolhação

\begin{tabular}{|c|c|c|c|}
\hline \multirow[b]{2}{*}{ Estratégia } & \multicolumn{2}{|c|}{ Estação } & \multirow[b]{2}{*}{ Média } \\
\hline & Primavera & Verão & \\
\hline \multicolumn{4}{|c|}{$\ldots \ldots \ldots$. . . kg MS/ha _...... } \\
\hline \multicolumn{4}{|c|}{ Massa total } \\
\hline $95 \%$ IL & $2.160 \mathrm{Ab}$ & $2.300 \mathrm{Ab}$ & $2.230 \mathrm{~b}$ \\
\hline $100 \%$ IL & $5.230 \mathrm{Aa}$ & $4.360 \mathrm{Aa}$ & $4.800 \mathrm{a}$ \\
\hline 28 dias & $2.140 \mathrm{Ab}$ & 2.870Aab & $2.510 \mathrm{~b}$ \\
\hline \multicolumn{4}{|c|}{ Folha } \\
\hline 95\% IL & $1.950 \mathrm{Ab}$ & $1.920 \mathrm{Ab}$ & $1.940 \mathrm{~b}$ \\
\hline $100 \%$ IL & $3.970 \mathrm{Aa}$ & $3.330 \mathrm{Aa}$ & $3.650 \mathrm{a}$ \\
\hline 28 dias & $1.900 \mathrm{Ab}$ & $2.190 \mathrm{Aab}$ & $2.040 \mathrm{~b}$ \\
\hline \multicolumn{4}{|c|}{ Colmo } \\
\hline 95\% IL & $1.66 \mathrm{Ab}$ & $245 \mathrm{Ab}$ & $205 b$ \\
\hline $100 \%$ IL & $9.08 \mathrm{Aa}$ & 783Аа & $845 a$ \\
\hline 28 dias & $1.16 \mathrm{Ab}$ & 432Aab & $274 b$ \\
\hline
\end{tabular}

${ }^{1}$ Massa de forragem acima da altura de resíduo de $15 \mathrm{~cm}$.

Médias seguidas da mesma letra minúscula na coluna e da mesma letra maiúscula nas linhas não diferem entre si $(\mathrm{P}>0,10)$ pelo teste Tukey.

estratégias baseadas na interceptação luminosa. A estratégia de desfolhação aos 95\% IL resultou em massas de forragem pré-pastejo significativamente menores, uma vez que os intervalos de pastejos foram mais curtos e as taxas de acúmulo de forragem menores (121 kg/ha.dia), como conseqüência da maior freqüência de desfolhação (Pedreira et al., 2007). Contudo, essa condição foi compensada pelo maior número de pastejos nos piquetes manejados a 95\% IL, proporcionando produção de forragem mais jovem, com menor proporção de material morto e provavelmente com melhor valor nutritivo.

A massa de folhas variou ( $\mathrm{P}=0,0027)$ com a estratégia de pastejo e foi afetada $(\mathrm{P}=0,0718)$ também pela interação estratégia $\times$ estação (Tabela 2). Em média, a estratégia de desfolhação aos $100 \%$ IL resultou na maior massa de folhas no momento da entrada dos animais. No entanto, na primavera, a massa de folhas obtida com desfolhação a cada 28 dias foi semelhante à encontrada com desfolhação aos 95\% IL, uma vez que, nesta estação houve déficit hídrico, o que prejudicou o crescimento. No verão, quando as condições climáticas se tornaram mais favoráveis e não havia restrições severas ao desenvolvimento das plantas, a desfolhação a cada 28 dias resultou em massa de folhas semelhante às obtidas com base na interceptação luminosa. Dessa forma, a proporção de folhas diminuiu e a de colmos aumentou.

A massa de colmos na forragem pré-pastejo foi afetada $(\mathrm{P}=0,0685)$ pela estratégia de pastejo $(\mathrm{P}<0,0001)$ e pela 
interação estratégia $\times$ estação (Tabela 2). Em média, as desfolhações aos 95\% IL e a cada 28 dias resultaram em menores massas de colmo na forragem pré-pastejo em comparação à desfolhação aos 100\% IL. A estratégia de desfolhação a cada 28 dias ocasionou variação na massa de colmos pré-pastejo, que foi semelhante à encontrada com desfolhações aos 95\%IL na primavera e com desfolhações aos $95 \%$ e aos $100 \%$ de IL durante o verão.

A porcentagem de folhas na massa de forragem prépastejo foi afetada pela estratégia de pastejo $(\mathrm{P}=0,0947)$, pela estação do ano $(\mathrm{P}=0,0117)$ e pela interação estratégia $\times$ estação $(P=0,0456)$. Entre as estações, em média, a desfolhação a cada 28 dias reduziu a proporção de folhas da primavera para o verão (Tabela 3) e aumentou a proporção de colmos com os pastejos sucessivos. Embora as estratégias de desfolhação aos 95 e 100\% IL não tenham diferido entre as estações, em média, a desfolhação aos 95\% IL resultou em maior proporção de folhas na massa de forragem prépastejo, apesar das menores massas de forragem (Tabela 2). Do mesmo modo, a forragem pré-pastejo nos piquetes sob desfolhações aos 100\% IL apresentou as menores porcentagens de folha, assim, a maior massa de forragem prépastejo (Tabela 2) foi resultado principalmente do alongamento de colmos, possivelmente reflexo da competição por luz no interior do dossel (Da Silva \& Corsi, 2003), causado pelo aumento na massa de folhas.

Tabela 3 - Porcentagem de folhas e colmos e índice de área foliar na massa de forragem pré-pastejo ${ }^{1}$ em capim-xaraés submetido a três estratégias de desfolhação

\begin{tabular}{|c|c|c|c|}
\hline \multirow[b]{2}{*}{ Estratégia } & \multicolumn{2}{|c|}{ Estação } & \multirow[b]{2}{*}{ Média } \\
\hline & Primavera & Verão & \\
\hline \multicolumn{4}{|c|}{$\begin{array}{r}\text { Folha } \\
\ldots \ldots \ldots \ldots\end{array}$} \\
\hline 95\% IL & $91,2 \mathrm{Aa}$ & $85,8 \mathrm{Aa}$ & $88,5 a$ \\
\hline 100\% IL & 81,ЗАа & 81,9Aa & $81,6 b$ \\
\hline 28 dias & $91,2 \mathrm{Aa}$ & $80,0 \mathrm{Ba}$ & $85,4 a b$ \\
\hline Média & $87,8 \mathrm{~A}$ & $82,5 \mathrm{~B}$ & \\
\hline & \multicolumn{2}{|c|}{ Colmo } & \\
\hline 95\% IL & 6,5Aab & $9,2 \mathrm{Aa}$ & \\
\hline $100 \%$ IL & $14,1 \mathrm{Aa}$ & $13,6 \mathrm{Aa}$ & \\
\hline 28 dias & $3,4 \mathrm{Bb}$ & $13,9 \mathrm{Aa}$ & \\
\hline Média & $8,0 \mathrm{~B}$ & $12,3 \mathrm{~A}$ & \\
\hline \multicolumn{4}{|c|}{ Índice de área foliar } \\
\hline 95\% IL & $4,47 \mathrm{Ab}$ & $3,16 \mathrm{Ab}$ & $3,81 b$ \\
\hline $100 \%$ IL & $6,57 \mathrm{Aa}$ & $5,19 \mathrm{Aa}$ & $5,88 a$ \\
\hline 28 dias & $3,71 \mathrm{Ab}$ & 3,85Aab & $3,78 b$ \\
\hline Média & $4,92 \mathrm{~A}$ & $4,07 \mathrm{~B}$ & \\
\hline
\end{tabular}

${ }^{1}$ Massa de forragem acima da altura de resíduo de $15 \mathrm{~cm}$.

Médias seguidas da mesma letra minúscula na coluna e da mesma letra maiúscula nas linhas não diferem entre si $(\mathrm{P}>0,10)$ pelo teste Tukey.
A proporção de colmos na massa de forragem prépastejo variou entre as estações do ano $(\mathrm{P}=0,0195)$ e foi afetada pela interação estratégia $\times$ estação $(\mathrm{P}=0,0388)$. $\mathrm{Na}$ média, as proporções de colmos observadas na primavera foram menores que no verão (Tabela 3). A estratégia de desfolhação aos $100 \%$ IL produziu forragem com maiores proporções de colmos em relação às demais estratégias de desfolhação na primavera. A desfolhação a cada 28 dias, por sua vez, gerou respostas diferentes entre as estações do ano. Na primavera, provavelmente em razão do balanço hídrico negativo, a forragem produzida apresentou menor proporção de colmos, como resultado das limitações para crescimento. Durante o verão, no entanto, o resultado obtido com as desfolhações a cada 28 dias foi semelhante ao encontrado com desfolhações aos 100\% IL, com menor proporção de folhas e maior proporção de colmos na massa de forragem pré-pastejo.

Em estudo com capim-bermuda cv. Tifton 85 (Cynodon ssp.) sob lotação contínua, 60 a $75 \%$ do crescimento das plantas foi proveniente do alongamento de colmos e não apenas do alongamento foliar (Pinto et al., 2001). A quantificação da participação de colmo na taxa de renovação de tecidos é importante, pois altera a relação folha:colmo da planta, o valor nutritivo da forragem, o comportamento ingestivo do animal em pastejo, seu consumo de forragem e, assim, interfere no desempenho animal e na eficiência de utilização da forragem (Silva, 1994).

A massa de material morto na massa de forragem pré-pastejo variou com a estratégia de pastejo $(\mathrm{P}=0,0121)$ e foi maior na estratégia de pastejo aos 100\% IL (280 kg MS/ha), como resultado do maior intervalo de pastejo. O pastejo aos 95\% IL gerou as menores massas de material morto, $70 \mathrm{~kg}$ MS/ha, em pré-pastejo, enquanto o pastejo a cada 28 dias resultou em condição intermediária e semelhante (130 kg MS/ha) à observada com desfolhações baseadas na interceptação luminosa. A proporção de material morto na massa de forragem pré-pastejo não variou entre as estratégias de pastejo e correspondeu, na média, a 3,8\% da massa de forragem.

O índice de área foliar pré-pastejo foi influenciado pela estratégia de pastejo ( $\mathrm{P}=0,0117)$, estação do ano $(\mathrm{P}=0,0171)$ e pela interação estratégia $\times$ estação $(\mathrm{P}=0,0906)$. Assim como para o componente folha, os maiores valores de índice de área foliar (Tabela 3) foram registrados na estratégia com intervalos de pastejo mais longos (100\% IL), tanto na primavera quanto no verão. O índice de área foliar pré-pastejo dos piquetes pastejados a cada 28 dias variou ao longo do experimento: na primavera, foi semelhante ao obtido com 95\% IL e, no verão, em virtude das condições mais favoráveis de crescimento, o índice de área foliar foi 
semelhante aos de ambas as estratégias de pastejo com base na interceptação luminosa, o que ilustra a variabilidade das estratégias de pastejo ao longo da estação de crescimento.

Brown \& Blaser (1968) discutiram a aplicação do conceito de índice de área foliar para aumentar a produção de matéria seca e argumentaram que outros fatores que afetam a produtividade por meio do índice de área foliar precisam ser considerados. O papel das folhas em aumentar o índice de área foliar é fundamental, enquanto altas taxas de crescimento podem ser alcançadas em um índice de área foliar que causa interceptação quase total da luz incidente. Dessa forma, dosséis pastejados com menores intervalos de descanso, 95\% IL, supostamente seriam mais eficientes em assimilar carbono (Pedreira \& Pedreira, 2007), mas, como o tempo de rebrotação é mais curto, o resultado é menor taxa média de acúmulo de forragem. Dosséis que são submetidos a intervalos mais longos de pastejo chegam a interceptar quase toda luz incidente, ou $100 \%$ IL, resultaram em maiores taxas de acúmulo de forragem durante a estação (173 kg MS/ha; Pedreira et al., 2007), mas com folhas de menor potencial individual de assimilação fotossintética de carbono (Pedreira

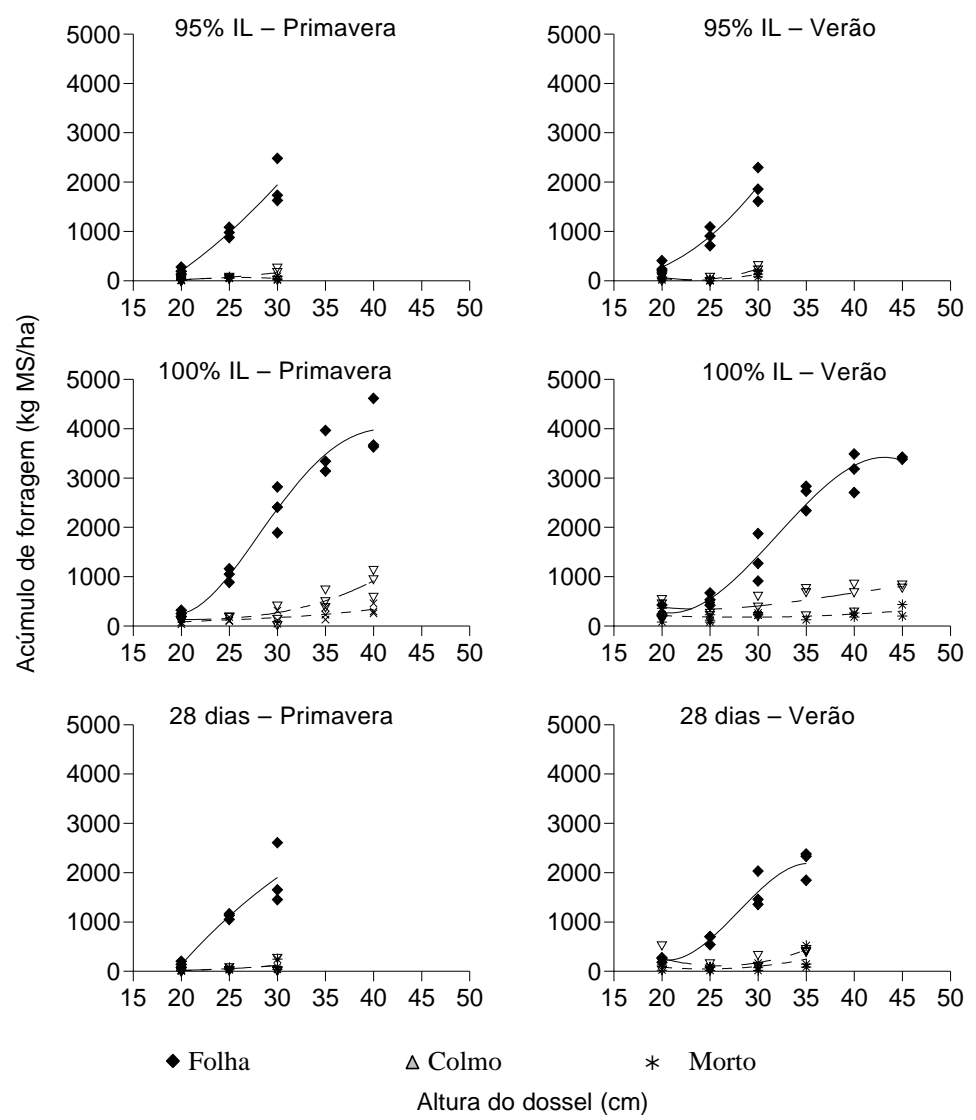

Figura 2 - Acúmulo dos componentes morfológicos ao longo do período de rebrotação em pastos de capim-xaraés submetidos a estratégias de pastejo rotativo.
\& Pedreira, 2007). Assim, quando se trata de produção de forragem para alimentação animal, é necessário saber de que forma ocorre o acúmulo de folhas, ponto-chave no sistema de produção, pois este é o componente morfológico mais importante do ponto de vista nutricional.

Um exame da dinâmica do acúmulo de forragem durante o período de rebrotação de sucessivos ciclos de pastejo revelou que no início o processo é caracterizado pelo acúmulo quase que exclusivo de folhas, até que o o dossel intercepte aproximadamente $95 \%$ da luz incidente e alcançe seu índice de área foliar crítico, ou seja, 3,7. A partir deste ponto, os componentes colmo e material morto começam a acumular de maneira significativa. No capim-xaraés, esse valor de índice de área foliar correspondeu à altura de dossel de $30 \mathrm{~cm}$ (Pedreira et al., 2007), independentemente da época do ano (Figura 2).

Esse mesmo padrão de resposta foi descrito anteriormente para os capins mombaça (Carnevalli et al., 2006) e tanzânia (Barbosa et al., 2007), nos quais o índice de 95\% de interceptação luminosa foi atingido nas alturas pré-pastejo de 90 e 70 cm, respectivamente. Em capim-tanzânia, pastejos realizados com 90\% IL resultaram em menor acúmulo total 
de matéria seca, porém acúmulo semelhante de folhas em relação à condição de 95\% IL (Barbosa et al., 2007). Os pastejos realizados com $100 \%$ IL resultaram em menor acúmulo total de forragem e de folhas, sugerindo que, antes de 95\% IL, a produção é limitada por interceptação subótima da luz incidente e depois de $95 \%$ IL por perdas excessivas por senescência e morte de tecidos (Barbosa et al., 2007), de forma semelhante àquela descrita por Parsons \& Penning (1988) e Parsons et al. (1988) para azevém-perene. Isso ratifica o fundamento biológico e dá suporte à aplicação do critério de 95\% IL como referência para a interrupção da rebrotação, uma vez que corresponde à condição em que a maior taxa de acúmulo de folhas é obtida, além de poder ser identificada no campo por meio da altura do dossel.

Neste estudo, o padrão de acúmulo de forragem resultante da estratégia de pastejo caracterizada por um período fixo de descanso de 28 dias variou entre aquele das estratégias de 95 e 100\% IL dependendo da época do ano e das condições de crescimento vigentes. Durante a primavera de 2005, com temperaturas médias mais baixas, menor precipitação pluvial e menor radiação luminosa, o período de descanso de 28 dias apresentou padrão de resposta mais próximo daquele correspondente à estratégia de 95\% IL . Nessas condições, a velocidade de crescimento das plantas é menor e o dossel necessita de maior número de dias para "fechar", ou seja, atingir 95\% IL ou 30 cm de altura), momento a partir do qual se intensifica o processo de competição por luz, e quando o acúmulo de colmos e a senescência aumentam (Figura 2). Por outro lado, no verão de 2006, com o aumento da disponibilidade de fatores de crescimento e, conseqüentemente, da maior velocidade de rebrotação, o período de descanso de 28 dias representou, em termos fisiológicos para a planta e estruturais para o dossel, um período mais longo, uma vez que menor número de dias foi necessário para atingir 95\% IL ou $30 \mathrm{~cm}$ de altura, resultando em um padrão de acúmulo de forragem mais próximo daquele de pastos submetidos à estratégia de 100\% IL. Esse padrão distinto de resposta entre épocas do ano ou condições de crescimento resultou em valores pré-pastejo de altura de dossel e massa de forragem diferentes para os mesmos 28 dias de descanso, sendo $30 \mathrm{~cm}$ e $2.140 \mathrm{~kg}$ MS/ha na primavera e 35 cm e $2.870 \mathrm{~kg}$ MS/ha no verão, respectivamente, em contraste com as estratégias de $95 \%$ com $30 \mathrm{~cm}$ e $2.160 \mathrm{~kg}$ MS/ha na primavera e $30 \mathrm{~cm}$ e $2.300 \mathrm{~kg}$ MS/ha no verão, respectivamente, e $100 \%$ IL com altura de $40 \mathrm{~cm}$ e $5.230 \mathrm{~kg}$ MS/ha na primavera e $45 \mathrm{~cm}$ e $4.360 \mathrm{~kg}$ MS/ha no verão, respectivamente. Isso comprova a inconsistência de respostas e a limitação de se adotar e, especialmente generalizar, um período de descanso fixo e definido a priori, uma vez que, dependendo da época do ano e das condições vigentes de crescimento, este período de descanso pode ser demasiadamente curto, o que levaria a perdas de produção em quantidade, ou demasiadamente longo, o que levaria a perdas de quantidade e qualidade, o que pode, em ambos os casos, resultar em degradação dos pastos.

O prolongamento do período de descanso ou do intervalo de pastejo além da condição em que o dossel intercepta 95\% da luz incidente resulta em aumento da massa de forragem com a entrada dos animais no piquete de $100 \%$ IL ou 28 dias durante o verão (Figura 2). Entretanto, esse aumento é resultado, basicamente, do acúmulo de colmos e de material morto, uma vez que o acúmulo de folhas se estabiliza ou diminui e ocorre aumento expressivo nos processos de alongamento de colmos e senescência (Moreno, 2004; Carnevalli et al., 2006; Barbosa et al., 2007) (Figura 3). Nessa condição, o maior acúmulo de forragem durante o perído de rebrotação compensa parcial ou totalmente o menor número de pastejos na estação de crescimento, ou seja, períodos de descanso mais longos (Carnevalli et al., 2006; Barbosa et al., 2007), embora o valor nutritivo da forragem em oferta seja reduzido.

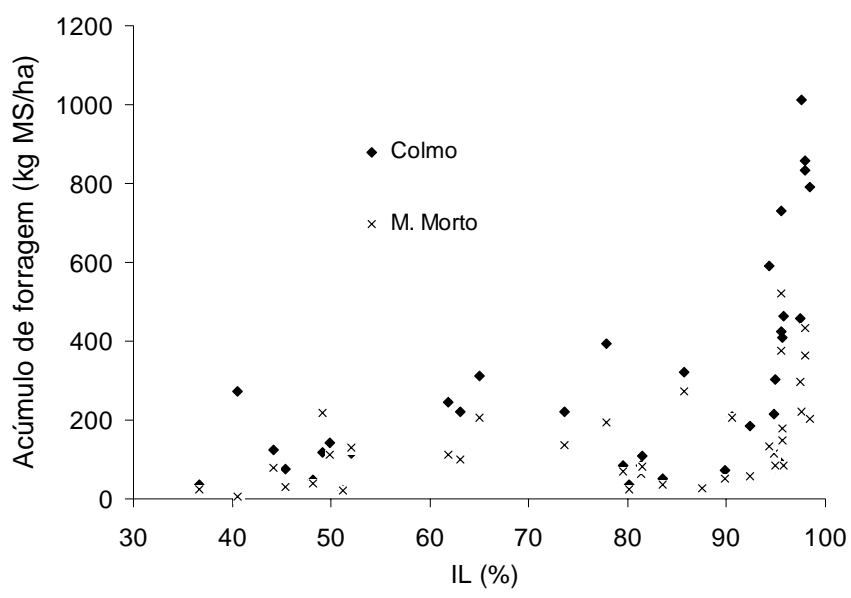

Figura 3 - Acúmulo de colmo e material morto ao longo do período de rebrotação em pastos de capim-xaraés submetidos a três estratégias de desfolhação.

\section{Conclusões}

O padrão de acúmulo de colmos, folhas e material morto difere entre as estratégias de desfolhação estudadas, mas é melhor na estratégia de desfolhação aos 95\% de interceptação luminosa. O manejo baseado em dias fixos e pré-determinados de descanso, apesar de facilitar o plane- 
jamento do pastejo rotativo, restringe as possibilidades de ganhos em eficiência do sistema, pois não gera um padrão uniforme de respostas fisiológicas de plantas e estruturais do dossel. Em vez disso, resulta em dosséis de estrutura variável, o que provavelmente afeta o consumo de forragem e o desempenho animal de forma variável e pouco previsível. Em regime de lotação rotativa, sugere-se que o manejo do pastejo do capim-xaraés seja feito observando a altura de entrada ou pré-pastejo de $30 \mathrm{~cm}$ e saída ou pós-pastejo de $15 \mathrm{~cm}$ para evitar acúmulo excessivo de colmos.

\section{Agradecimentos}

À Fundação de Amparo a Pesquisa do Estado de São Paulo (FAPESP), pelo apoio financeiro na forma de bolsa de mestrado ao primeiro autor.

\section{Literatura Citada}

BARBOSA, R.A.; NASCIMENTO JR., D.; EUCLIDES, V.P.B. et al. Capim-tanzânia submetido a combinações entre intensidade e freqüência de pastejo. Pesquisa Agropecuária Brasileira, v.42, n.3, p.329-340, 2007.

BROWN, R.H.; BLASER, R.E. Leaf area index in pasture growth. Herbage Abstracts, v.38, n.1, p.1-9, 1968.

BUTTLER, J.L.; BRISKE, D.D. Population structure and tiller demography of the buchgrass Schizachyrium scoparium in response to herbivory. Oikos, v.51, p.306-312, 1988.

CARNEVALLI, R.A.; DA SILVA, S.C.; BUENO, A.A.O. et al. Herbage production and grazing losses in Panicum maximum cv. Mombaça under four grazing managements. Tropical Grasslands, v.40, p.165-176, 2006.

DA SILVA, S.C.; CORSI, M. Manejo do pastejo. In: SIMPÓSIO SOBRE MANEJO DA PASTAGEM, 20., 2003, Piracicaba. Anais... Piracicaba: Fundação de Estudos Agrários Luiz de Queiroz, 2003. p.155-186.

DA SILVA, S.C.; SBRISSIA, A.F. A planta forrageira no sistema de produção. In: SIMPÓSIO SOBRE MANEJO DA PASTAGEM, 17., 2001, Piracicaba. Anais.... Piracicaba: Fundação de Estudos Agrários Luiz de Queiroz, 2001. p.71-88.

EMBRAPA ACRE. Sistemas de produção de gado de corte. [2003]. Disponível em: <http://sistemasdeproducao.cnptia. embrapa.br/FontesHTML/BovinoCorte/BovinoCorteAcre/ index.htm>. Acesso em: 10/2/2005.

EMPRESA BRASILEIRA DE PESQUISA AGROPECUÁRIA EMBRAPA. Centro Nacional de Pesquisa de Solos (Rio de Janeiro, RJ). Sistema brasileiro de classificação de solos. Rio de Janeiro, 1999. 412p.

MELLO, A.C.L.; PEDREIRA, C.G.S. Respostas morfológicas do capim-tanzânia (Panicum maximum Jacq. cv. Tanzânia-1) irrigado à intensidade de desfolha sob lotação rotacionada. Revista Brasileira de Zootecnia, v.33, n.2, p.282-289, 2004 MISLEVY, P.; MOTT, G.O.; MARTIN, F.G. Screening perennial forages by mob-grazing technique. In: INTERNATIONAL GRASSLAND CONGRESS, 14., 1981, Lexington. Proceedings... Lexington: 1981. p.516-519.

MORENO, L.S.B. Produção de forragem de capins do gênero Panicum e modelagem de respostas produtivas e morfofisiológicas em função de variáveis climáticas. 2004. 86f. Dissertação (Mestrado em Ciência Animal e Pastagens) Escola Superior de Agricultura Luiz de Queiroz, Piracicaba, 2004.

MURPHY, J.S.; BRISKE, D.D. Regulation of tillering by apical dominance - chronology, interpretive value, and current perspectives. Journal of Range Management, v.45, n.5, p.419-429, 1992.

NABINGER, C.; PONTES, L.S. Morfogênese de plantas forrageiras e estrutura do pasto. In: REUNIÃO ANUAL DA SOCIEDADE BRASILEIRA DE ZOOTECNIA, 38., 2002, Piracicaba. Anais... Piracicaba: Sociedade Brasileira de Zootecnia, 2002. p.755-771.

PARSONS, A.J.; JOHNSON, I.R.; HARVEY, A. Use of a model to optimize the interactions between frequency and severity of intermittent defoliation and to provide a fundamental comparison of the continuous and intermittent defoliation of grass. Grass and Forage Science, v.43, p.49-59, 1988.

PARSONS, A.J.; PENNING, P.D. The effect of duration of regrowth on photosynthesis, leaf death and average rate of growth in a rotational grazed sward. Grass and Forage Science, v.43, p.15-27, 1988

PEDREIRA, B.C.; PEDREIRA, C.G.S. Fotossíntese foliar do capimxaraés [Brachiaria brizantha (A. Rich.) Stapf. cv. Xaraés] e modelagem da assimilação potencial de dosséis sob estratégias de pastejo rotativo. Revista Brasileira de Zootecnia, v.36, n.4, p.773-779, 2007

PEDREIRA, B.C.; PEDREIRA, C.G.S.; DA SILVA, S.C. Estrutura do dossel e acúmulo de forragem de Brachiaria brizantha cultivar Xaraés em resposta a estratégias de pastejo. Pesquisa Agropecuária Brasileira, v.42, n.2, p.281-287, 2007.

PINTO, L.F.M.; DA SILVA, S.C.; SBRISSIA, A.F. et al. Dinâmica de acúmulo de matéria seca em pastagens de Tifton 85 sob pastejo. Scientia Agricola, v.58, n.3, p.439-447, 2001.

SANTOS, P.M.; CORSI, M.; BALSALOBRE, M.A.A. Efeito da freqüência do pastejo e da época do ano sob a produção e qualidade em Panicum maximum cvs. Tanzânia e Mombaça. Revista Brasileira de Zootecnia, v.28, n.2, p.244-249, 1999.

LITTELL, R.C.; MILLIKEN, G.A.; STROUP, W.W. et al. Sas for Mixed Models. 2.ed. Cary: SAS Institute, 2006. (CD-ROM).

SILVA, D.S.; GOMIDE, J.A.; QUEIROZ, A.C. et al. Pressão de pastejo em pastagem de capim-elefante anão (Pennisetum purpureum, Schum. Cv. Mott). 2. Valor nutritivo, consumo de pasto e produção de leite. Revista Brasileira de Zootecnia, v.23, p.453-464, 1994.

WELLES, J.M.; NORMAN, J.M. Instrument for indirect measurement of canopy architecture. Agronomy Journal, v.83, p.818-825, 1991.

WOLFINGER, R. Covariance structure selection in general mixed models. Community of Statistics - Simulation, v.22, n.4, p.1079-1106, 1993. 